\title{
Evaluation and characterization of thyroid-disrupting activities in soil samples along the Second Songhua River, China
}

\author{
Dongdong Kong ', Yafei Wang ${ }^{a}$, Jinsheng Wang ${ }^{a}$, Yanguo Teng ${ }^{a}, \mathrm{Na} \mathrm{Li}^{\mathrm{b}}$, Jian Li ${ }^{\mathrm{a}, *}$ \\ ${ }^{a}$ Engineering Research Center of Groundwater Pollution Control and Remediation, Ministry of Education, College of Water Sciences, Beijing Normal Uni- \\ versity, Beijing 100875, China \\ b State Key Laboratory of Environmental Aquatic Chemistry, Research Center for Eco-Environmental Sciences, Chinese Academy of Sciences, P.O. Box 2871, \\ Beijing 100085, China
}

\section{A R T I C L E I N F O}

\section{Article history:}

Received 15 April 2016

Received in revised form

5 August 2016

Accepted 8 August 2016

Available online 13 August 2016

Keywords:

In vitro bioassay

Thyroid receptor

Soil sample

Thyroid-disrupting chemicals

\begin{abstract}
A B S T R A C T
In this study, a recombinant thyroid receptor (TR) gene yeast assay combined with Monte Carlo simulation were used to evaluate and characterize soil samples collected from Jilin (China) along the Second Songhua River, for their ant/agonist effect on TR. No TR agonistic activity was found in soils, but many soil samples exhibited TR antagonistic activities, and the bioassay-derived amiodarone hydrochloride equivalents, which was calculated based on Monte Carlo simulation, ranged from not detected (N.D.) to $35.5 \mu \mathrm{g} / \mathrm{g}$. Hydrophilic substance fractions were determined to be the contributors to TR antagonistic activity in these soil samples. Our results indicate that the novel calculation method is effective for the quantification and characterization of TR antagonists in soil samples, and these data could provide useful information for future management and remediation efforts for contaminated soils.
\end{abstract}

(c) 2016 Elsevier Inc. All rights reserved.

\section{Introduction}

The thyroid hormones (THs) are involved in several important physiological processes, including energy metabolism, tissue differentiation and organ growth (Murk et al., 2013). Alterations of circulating TH levels are well-documented consequences of exposure to thyroid disrupting chemicals (TDCs) (Kirkegaard et al., 2011; Levy-Bimbot et al., 2012). A large number of environmental chemicals and stressors are known to disrupt the function of $\mathrm{TH}$ system, including polychlorinated biphenyls (PCBs), organochlorine pesticides (OCPs), dioxins, polybrominated flame retardants, phenols, perfluorinated chemicals, phthalates and perchlorate (Boas et al., 2012). These chemicals can interfere with the synthesis, release, transport through blood, metabolism, and clearance of THs, and also thyroid receptors (TRs) and their transcriptional activity by acting as TR agonists or antagonists (Buha et al., 2013; Skipor et al., 2012).

Research on thyroid disruption has been dominated by studies on the aquatic environment, for example, TDCs in samples collected from drinking water, waste water, and surface water have been reported (Li et al., 2014a; Northcott and Jones, 2000; Shi et al., 2016). Kannan et al. (2003) found that the soil extracts elicited estrogenic and androgenic activities in cotton field soils from

\footnotetext{
* Corresponding author.

E-mail address: lijian@bnu.edu.cn (J. Li).
}

Georgia and South Carolina, USA. These years, accumulating evidences have documented that a variety of chemical substances, detected in soil, such as PCBs, OCPs, and phenols, have been proved to show the thyroid-disrupting activities (Han et al., 2013; Xu et al., 2015). Once contaminated, the physical and chemical properties of the soil would change, which might lead to soil hardening, the decrease of soil fertility, and detrimental impact on the growth of plants, soil animals and micro-organism (Floch et al., 2011; Robson et al., 2013). Moreover, some TDCs in soil exhibit persistence, bioaccumulation in the tissues of organisms, and biomagnifications through the food chain (Mnif et al., 2011). Further evidences showed that inhalation and contact with TDCs in soil pose a risk to human and wildlife (Burns et al., 2013). However, the data about the thyroid-disrupting activities from soil samples is limited or even unavailable.

Assessing the risks of thyroid disruption in soil will need to improve the detection throughput of TDCs in the environment. The uncertainties of thyroid disrupting potentials varied from the antagonistic or synergistic effects, the possibilities of additives, the difference of TDCs' mechanism(s)-of-action and also the ways of TDCs' results interpretation and extrapolation (Crofton, 2008). Monte Carlo simulation, to calculate the risks of measured $\mathrm{TH}$ agonists and antagonists, have been proved to be an effective method to assess the endocrine-disrupting potency of mixtures (Shi et al., 2013; Li et al., 2015).

Data just on the extractable or total concentration of the single chemical may be in some measure inadequate when assessing 
environmental significance. There are also other factors, such as its extractability, sequestration by environmental solids, speciation or 'form', and bioavailability, accounting for the risks (Northcott and Jones, 2000). To guarantee the efficiency of potential TDCs extraction, the mixture of organic extracts from water samples was further classified and separated by polarity, and then the bioassays are conducted to detect their thyroiddisrupting activities, respectively (Ma et al., 2007; Wu et al., 2009; Li et al., 2015). After that, the profiles and identifications of the potential TDCs were conducted by the bioassay-directed fractionation approach.

Jilin City, located along the Second Songhua River (SSR) - the largest tributary of the Songhua River, is one of the most important agricultural and chemical industry centers in northeast China (Li et al., 2015). Literatures indicated that some persistent organic contaminants, such as PCBs and OCPs, entered the soil environment in the SSR basin during the industrial and/or agricultural processes, and some of these compounds may have thyroid-disrupting potential (Xing et al., 2005; Wang et al., 2012). However, information on the thyroid-disrupting activities of soils in Jilin City is limited. The recombinant gene yeast assays have been demonstrated to be suitable tools to detect and quantify the endocrine-disrupting chemicals, and their results could be used for risk assessment (Li et al., 2010a; WHO-UNEP, 2012). Thanks to the features of perform-friendly, time-saving and cost-inexpensively, the bioassays have shown their satisfactory sensitivity and reproducibility in application (Bittner et al., 2015).

A batch of recombinant gene yeast assays were used to investigate the endocrine disrupting activities of soil samples in Jilin City along SSR, including estrogenic, androgenic and thyroid disrupting activities (Li et al., 2015). The present study focused on the detection of thyroid disrupting activities of soil samples from Jilin City along SSR, using the recombinant thyroid receptor gene yeast assay combined with Monte Carlo simulation. The different fractions divided by polarity were also tested and then their results were analyzed to identify the major fraction responsible for the thyroid-disrupting potency. Besides, the anti-estrogenic and antiandrogenic activities in this area have been previously reported ( $\mathrm{Li}$ et al., 2015).

\section{Materials and methods}

\subsection{Chemicals}

3,3',5-Triiodo-L-thyronine ([T3], 95\%) and dimethylsulfoxide ([DMSO], 99.5\%) were purchased from Sigma Chemical (St. Louis, MO, USA). Amiodarone hydrochloride (AH) was purchased from Shanghai Pharmaceutical (Shanghai, China). The stock solutions of all compounds were dissolved in DMSO. HPLC-grade dichloromethane (DCM), methanol and hexane were purchased from Fisher Scientific (Fair Lawn, NJ). Silica $(60-200 \mu \mathrm{m})$, and $\mathrm{Al}_{2} \mathrm{O}_{3}(50-200 \mu \mathrm{m})$ were purchased from Acros Organics (Geel, Belgium).

\subsection{Sample collection and processing}

Nine soil samples were collected from the surface layer (upper 20-30 cm) in August 2011 (Fig. 1). Each soil sample (500 g) was kept into a glass bottle, which was pre-cleaned with DCM, and then stored at $-20^{\circ} \mathrm{C}$ for further analysis. All of the samples were under treatment within $72 \mathrm{~h}$.

Soil pH and organic carbon were measured according to the National Environmental Quality Standards for Soils of China (GB15618, 1995).

\subsection{Soil organic extract preparation}

After being freeze-dried and meshed, $20 \mathrm{~g}$ of each soil sample was extracted with $200 \mathrm{~mL}$ of DCM via Soxhlet extraction, and the resulting extracts were evaporated to $1 \mathrm{~mL}$ under a nitrogen stream. Subsequently, $0.5-\mathrm{mL}$ aliquots were evaporated to near dryness under a gentle flow of nitrogen gas and then redissolved in $0.5 \mathrm{~mL}$ of DMSO. The remaining $0.5-\mathrm{mL}$ aliquots were then carefully moved to columns containing $10 \mathrm{~g}$ of silica and $10 \mathrm{~g}$ of $\mathrm{Al}_{2} \mathrm{O}_{3}$ (Ma et al., 2007). The column was eluted with $15 \mathrm{~mL}$ of hexane to yield a nonpolar fraction, with $70 \mathrm{~mL}$ of a hexane/DCM $(\mathrm{v} / \mathrm{v}=7: 3)$ mixture to obtain a medium-polar fraction, and with $30 \mathrm{~mL}$ of methanol to acquire a polar fraction (Xiao et al., 2006; Wang et al., 2008). The sub-fractions were also evaporated to dryness under a gentle nitrogen flow and re-dissolved in $0.5 \mathrm{~mL}$ of DMSO. The raw organic extracts and three sub-fractions were kept at $-20^{\circ} \mathrm{C}$ until prior to being used in the bioassay. Test solutions with six different concentrations were obtained by 2 -fold dilution

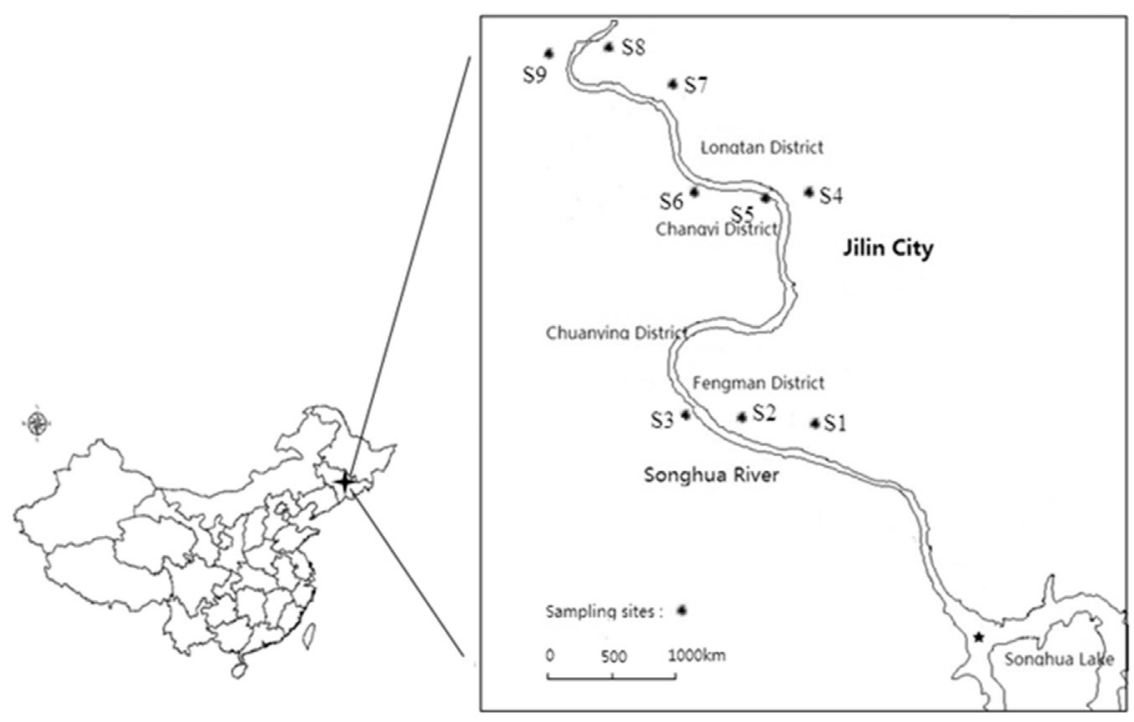

Fig. 1. Sampling sites in Jilin City along the Second Songhua River. 

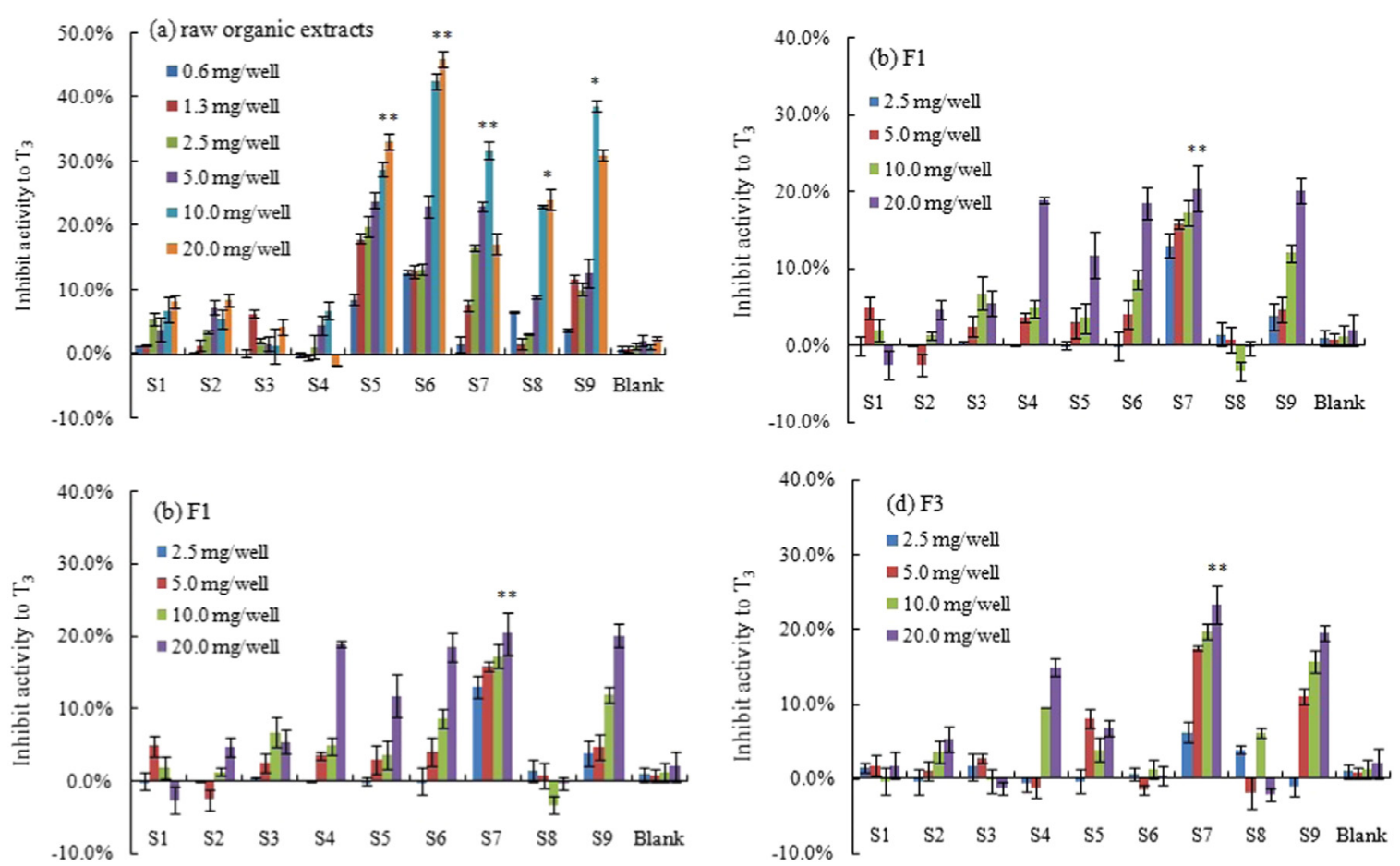

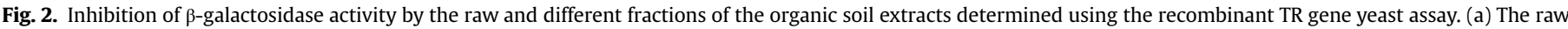

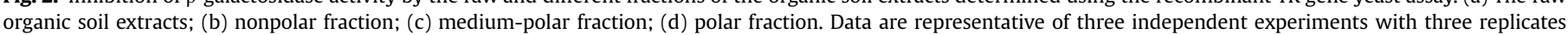
each. Significant differences were indicated by asterisks ( ${ }^{*} \mathrm{p}<0.05$, $\left.{ }^{* *} \mathrm{p}<0.01\right)$. TR: thyroid receptor.

of each extract. DMSO worked as a solvent control for the bioassay (Luo et al., 2011), and quartz sand was used as procedural blank.

\subsection{The recombinant gene yeast assay}

Yeast strains transfected with the respective TR gene were produced in our laboratory with a yeast two-hybrid assay system and selected by growth on synthetic dextrose (SD) medium (lacking tryptophan and leucine, SD/-Leu/-Trp) in term of the method described previously in our paper (Li et al., 2010a).

The bioassays, both the agonistic and antagonistic activity tests included, were conducted in accordance with the procedure described by Li et al. (2010a). All of the experiments were performed in triplicate and the means of results were used for optimization. The statistical significance was evaluated by Excel using Student's $t$-test according to equal or unequal variance with the solvent control group. T3 was selected as a positive control for agonistic activity, and $\mathrm{AH}$ was selected as a positive control for antagonistic activity against TR. Each experimental group was comprised of the sample, the positive control, the negative control (DMSO) and the procedural blank. The equations reported by Gaido et al. (1997) were used to calculate the $\beta$-galactosidase activity.

\subsection{Cytotoxicity}

To ensure that the resulting effects from the bioassay were caused by real agonistic/antagonistic responses other than cytotoxicity, viability was also evaluated in cells exposed to soil samples at the maximum assay concentration. Yeast cells were plated as in the original assay and then exposed for $2 \mathrm{~h}$ to exposure medium in the presence of soil samples. The change in cell density $\left(\mathrm{OD}_{600 \mathrm{~nm}}\right)$ in the assay medium was used to determine the cell viability spectrophotometrically. The results were acceptable when the ratio $\left(\mathrm{OD}_{600 \mathrm{~nm}}\right.$-exposure medium $\left./ \mathrm{OD} 600_{\text {nm-blank medium }}\right)$ ranged from $80 \%$ to $120 \%$.

\subsection{Data analysis}

The data of each assay are relative to the solvent control and values were presented as means \pm SD $(n=3)$. For each sample, only results obtained at induct/inhibit activity to $\mathrm{T} 3$ higher than $10 \%$ were included in statistical analysis. P-values less than 0.05 were considered significant. The bioassay-derived equivalent concentration was calculated by comparing the ant/agonistic activity of the soil samples with the concentrations of the standard chemicals (Shi et al., 2013). The equivalent concentration is not a single point but rather a range calculated based on Monte Carlo simulation using the Crystal ball (11.1.1.0.00 version, Oracle Corporation, CA, USA). The maximum, minimum, and mean values and the distribution of the equivalent concentrations were obtained.

\section{Results and discussion}

\subsection{Cell viability and system credibility}

To examine the $\beta$-galactosidase inhibition induced by the interaction of TDCs with TR, we tested the proficiency of the bioassay system, as described in the Supporting information (SI). Results indicated that the soil organic extracts did not inhibit the $\beta$-galactosidase activity (Fig. S1, Section 1 in SI). To account for stimulatory or toxic matrix effects on the yeast, we determined the cytotoxicity values, which revealed no significant variation in yeast cell viability (Fig. S2, Section 2 in SI).

\subsection{TR ant/agonistic activity of the organic extracts of the soil}

The TR agonistic activities of the raw organic extracts of the soil were not detected by the yeast assay (Fig. S3, Section 3 in SI). It is noteworthy that significant effects of TR antagonists were found at S5 and S6. The concentration-dependent curves of the TR 
Table 1

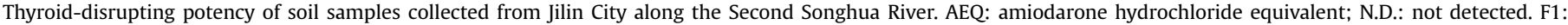
nonpolar fraction; F2: medium-polar fraction; F3: polar fraction.

\begin{tabular}{|c|c|c|c|c|c|c|c|c|c|c|c|c|}
\hline \multirow{2}{*}{$\begin{array}{l}\text { Sample } \\
(\mu \mathrm{g} / \mathrm{g})\end{array}$} & \multicolumn{3}{|c|}{ Raw organic extract } & \multicolumn{3}{|l|}{ F1 } & \multicolumn{3}{|l|}{ F2 } & \multicolumn{3}{|l|}{ F3 } \\
\hline & $\min$ & $\max$ & mean & $\min$ & $\max$ & mean & $\min$ & $\max$ & mean & $\min$ & $\max$ & mean \\
\hline S1 & N.D. & N.D. & N.D. & N.D. & N.D. & N.D. & N.D. & N.D. & N.D. & N.D. & N.D. & N.D. \\
\hline S2 & N.D. & N.D. & N.D. & N.D. & N.D. & N.D. & N.D. & N.D. & N.D. & N.D. & N.D. & N.D. \\
\hline S3 & N.D. & N.D. & N.D. & N.D. & N.D. & N.D. & N.D. & N.D. & N.D. & N.D. & N.D. & N.D. \\
\hline S4 & N.D. & N.D. & N.D. & 0.9 & 3.3 & 1.6 & N.D. & N.D. & N.D. & 1.5 & 1.9 & 1.8 \\
\hline S5 & 22.7 & 42.1 & 35.5 & 0.2 & 1.5 & 1.1 & 6.5 & 12.2 & 10.8 & N.D. & N.D. & N.D. \\
\hline S6 & 21.0 & 33.5 & 25.2 & 1.2 & 3.2 & 1.8 & 22.5 & 33.9 & 26.9 & N.D. & N.D. & N.D. \\
\hline S7 & 6.5 & 73.2 & 19.8 & 4.1 & 10.8 & 6.9 & 8.3 & 12.9 & 10.0 & 5.7 & 11.1 & 7.5 \\
\hline S8 & 8.2 & 13.5 & 11.0 & N.D. & N.D. & N.D. & 10.4 & 13.9 & 12.5 & N.D. & N.D. & N.D. \\
\hline S9 & 8.6 & 9.2 & 8.9 & 2.3 & 4.2 & 3.3 & 3.3 & 3.8 & 3.5 & 3.4 & 4.6 & 4.3 \\
\hline Blank & N.D. & N.D. & N.D. & N.D. & N.D. & N.D. & N.D. & N.D. & N.D. & N.D. & N.D. & N.D. \\
\hline
\end{tabular}

antagonistic activities for these samples were depicted in Fig. 2 a. The blank samples did not disrupt the TR gene expression (Fig S4, Section 3 in SI). The corresponding $\mathrm{AH}$ equivalents (AEQ $\mathrm{Arw}_{\text {}}$ ) evaluated by the Monte Carlo simulation ranged from N.D. to $35.5 \mu \mathrm{g} / \mathrm{g}$ AH (Table 1). The S5 and S6, where the highest activity was found, are located in the chemical engineering region of the city, concentrated with main industrial activities, such as chemical, steel and oil refining industries.

Few reports on the TR-disrupting effects of the soil samples are available, but exclusively TR-antagonistic activity in sediment samples collected from the Guanting Reservoir, Beijing, was previously reported (Li et al., 2014b). The AH equivalent concentration in the sediment organic extracts ranged from $25.4 \pm 3.7$ to $176.9 \pm 18.0 \mu \mathrm{g} / \mathrm{g} \mathrm{AH}$ and were comparable to those of the soil samples mentioned above. This might threaten human health in some extent and further risk assessment of thyroid disruption in such soil matrix is recommended to protect human from possible threats. Gutlebl et al. (2005) used the T-screen method and also reported that apolar sediment extracts exhibited TR-antagonist activities. Furthermore, this finding was supported by the hypothesis that any TR-agonistic activity present in low amounts would have been masked by the levels of antagonistic activity, which were higher (Alvarez-Muñoz et al., 2014).

The highest activity (S5 and S6) was found in the chemical engineering area of the city, whereas less than $10.0 \%$ of inhibit activity to T3 were observed in the agriculture area (S1, S2 and S3). Jálová et al. (2013) suggested that sources of EDCs are associated with larger urbanized and industrial areas. This may be because some chemicals, for example, brominated flame retardants (BFRs), PCBs, and phenols, that are used or produced in industrial processes have been found to dock in the ligand-binding domain of TR and act as TR antagonists (Boas et al., 2012; Murk et al., 2013; Li et al., 2008). Most of these chemicals are components of widespread pollution in China and have been frequently detected in soil environments (Zhu et al., 2014; Xing et al., 2005; Wang et al., 2012). The accumulation of these chemicals in the soil environment is of increasing concern because of their impacts on food safety and potential health risks. Crops may uptake of these chemicals via the soil-root route and/or the soil-air-plant route, which may lead to an increasing health risk caused by the consumption of these contaminated-crops. In addition, the migration and transformation of these chemicals from the soil environment to the air, surface water and/or groundwater through vaporization, diffusion and flow would also trigger subsequent ecological problems. On the other hand, some TDCs, such as PCBs and phenols, were found in water and sediments from Songhua River (Cui et al., 2016; Wang et al., 2012). These pollutants from river water might affect the soil system through irrigation (Abegunrin et al., 2016).

\subsection{AEQs of different fractions}

To characterize the responsible compounds, the organic extracts from the soil samples were classified and separated by polarity, and then the TR antagonistic activity of each fraction was determined respectively. Some of the fractions exhibited antagonistic TR activities that inhibited $\beta$-galactosidase expression (Fig. 2b-d).

The TR antagonistic activities ranged from N.D. to $6.9 \mu \mathrm{g} / \mathrm{g} \mathrm{AH}$ in the nonpolar fraction and from N.D. to $7.5 \mu \mathrm{g} / \mathrm{g} \mathrm{AH}$ in the polar fraction (Table 1). The medium-polar fraction showed higher TR antagonistic effects, with an activity range of N.D.-26.9 $\mu \mathrm{g} / \mathrm{g}$ AH. To identify the responsible fractions, the contribution rates of the fractions for S5-S9, which exhibit obvious TR-antagonistic activities, were calculated as shown in Fig. 3. As seen in this figure, the contribution rates of the polar and nonpolar fractions were lower than $40.0 \%$. Furthermore, the medium-polar fraction was estimated to account for $31.3-97.1 \%$ of the $\sum A E Q_{F 1-3}$, suggesting that these medium-polar chemicals play an important role in the observed TR-antagonistic activities.

The medium-polar fraction contains phthalate esters (PAEs), PAHs and OCPs (Luo et al., 2011; Wu et al., 2013), and a relevant report suggested that some PAEs, such as dibutyl phthalate and diethyl hexyl phthalate, exhibit anti-thyroid hormone effects and contribute to the TR-antagonistic activities observed in drinking water and water sources (Shi et al., 2016; Li et al., 2010b). Moreover, the present study also indicates that a realistic in vitro risk assessment for soil TDCs should include testing of the polar and nonpolar soil extracts, in consistent with the previous results reported by Gutleb et al. (2007) and Montaño et al. (2013), who detected the thyroid hormone-disturbing activities in apolar and polar sediment extracts.

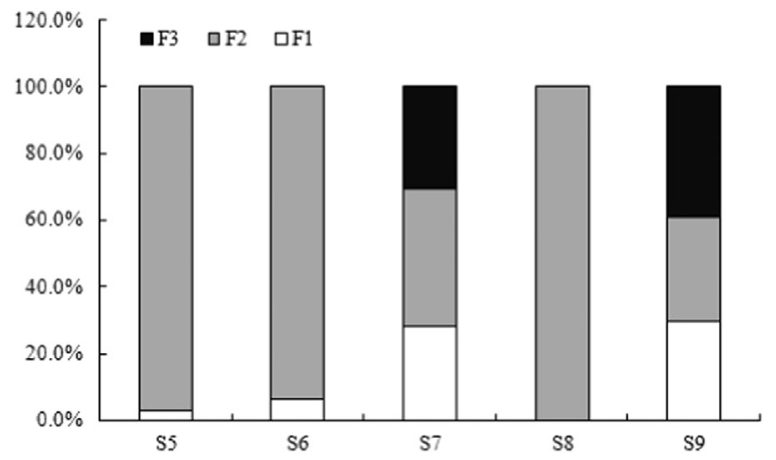

Fig. 3. TR antagonists in different fractions of the organic soil extracts. AEQ amiodarone hydrochloride equivalent; F1: nonpolar fraction; F2: medium-polar fraction; F3: polar fraction. 


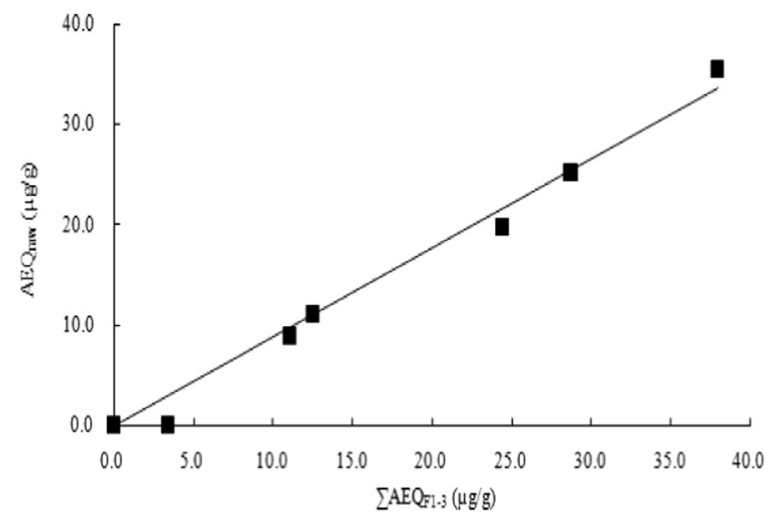

Fig. 4. Correlation between AEQraw and $\sum A E Q F 1-3$. AEQraw: amiodarone hydrochloride equivalent for raw organic extracts of soil samples; $\Sigma$ AEQF1-3: the sum of the amiodarone hydrochloride.

\subsection{Correlation between $A E Q_{\text {raw }}$ and $\sum A E Q_{F 1-3}$}

Based on the TEQ approach, $\sum \mathrm{AEQ}_{\mathrm{F} 1-3}$ accounted for 106.85$124.44 \%$ of $\mathrm{AEQ}_{\text {raw, }}$ while a 2 nd-order polynomial regression analysis using the calculated AEQ values showed a positive correlation between $\mathrm{AEQ}_{\text {raw }}$ and $\sum \mathrm{AEQ}_{\mathrm{F} 1-3}(\mathrm{R}>0.9 ; p<0.05$; Fig. 4).

Complex environmental samples analyzed using the same in vitro bioassay usually exhibit nonparallel dose-response relationships, which means that it is difficult to simplify the interpretation of the data and to compare the results with a well-characterized standard chemical (Shi et al., 2013). In the present study, a novel approach for evaluating the concentrations of TR antagonists based on Monte Carlo simulation was used to facilitate the quantitative assessment and characterization of the toxic potency of soil samples. Monte Carlo analysis is a computer-based method which uses statistical sampling techniques in obtaining a probabilistic approximation to the solution of a mathematical equation or model. Thus, Monte Carlo simulation allows for further accommodation of the uncertainties and quantitation of the variability (Hoefling et al., 2011). Shi et al. (2013) used a similar method to evaluate the measured concentrations of thyroid hormone agonists and antagonists and suggested that this method is suitable not only for the equivalency estimation of environment water samples but also for improving the accuracy of mass balance analysis. Furthermore, in this research, this novel method was proved to be an effective method to quantify and characterize the TR antagonists of soil samples.

\section{Conclusion}

In summary, a recombinant TR gene yeast assay was used to evaluate and characterize the TR agonistic and antagonistic activities of soil samples collected from Jilin along the SSR. Our results suggest that soil samples may exhibit TR-antagonistic activities. Medium-polar chemicals may play an important role in TRantagonistic activities in soil samples. This work contributes to understanding the TR-disrupting effects and identifying TR antagonists and provides useful information for future management and remediation efforts.

\section{Acknowledgment}

This study was supported by the National Natural Science Foundation of China (41001351), the Fundamental Research Funds for the Central Universities (2012LYB35), the Major Science and
Technology Program for Water Pollution Control and Treatment (2014ZX07201-010) and the China Scholarship Council (201606045023).

\section{Appendix A. Supplementary material}

Supplementary data associated with this article can be found in the online version at http://dx.doi.org/10.1016/j.ecoenv.2016.08. 005.

\section{References}

Abegunrin, T.P., Awe, G.O., Idowu, D.O., Adejumobi, M.A., 2016. Impact of wastewater irrigation on soil physico-chemical properties, growth and water use pattern of two indigenous vegetables in southwest Nigeria. Catena 139 $167-178$.

Alvarez-Muñoz, D., Indiveri, P., Rostkowski, P., Horwood, J., Greer, E., Minier, C., Pope, N., Langston, W.J., Hill, E.M., 2014. Widespread contamination of coastal sediments in the Transmanche Channel with anti-androgenic compounds. Mar. Pollut. Bull.

Bittner, M., Jarque, S., Hilscherova, K., 2015. Polymer-immobilized ready-to-use recombinant yeast assays for the detection of endocrine disruptive compounds. Chemosphere 132, 56-62.

Boas, M., Feldt-Rasmussen, U., Main, K.M., 2012. Thyroid effects of endocrine disrupting chemicals. Mol. Cell. Endocrinol. 355, 240-248.

Buha, A., Antonijević, B., Bulat, Z., Jaćević, V., Milovanović, V., Matović, V., 2013. The impact of prolonged cadmium exposure and co-exposure with polychlorinated biphenyls on thyroid function in rats. Toxicol. Lett. 221, 83-90.

Burns, C.J., Mclntosh, L.J., Mink, P.J., Jurek, A.M., Li, A.A., 2013. Pesticide exposure and neurodevelopmental outcomes: review of the epidemiologic and animal studies. J. Toxicol. Environ. Health B: Crit. Rev. 16, 395-398.

Crofton, K.M., 2008. Thyroid disrupting chemicals: mechanisms and mixtures. Int. J. Androl. 31 (2), 209-223.

Cui, S., Fu, O., Guo, L., Li, Y.F., Li, T.X., Ma, W.L., Wang, M., Li, W.L., 2016. Spatialtemporal variation, possible source and ecological Risk of PCBs in sediments from Songhua River, China: effects of $\mathrm{PCB}$ elimination policy and reverse management framework. Mar. Pollut. Bull. 106, 109-118.

Floch, C. Chevremont, A.-C., Joanico, K., Capowiez, Y., Criquet, S., 2011. Indicators of pesticide contamination: Soil enzyme compared to functional diversity of bacterial communities via Biolog ${ }^{\mathbb{R}}$ Ecoplates. Eur. J. Soil Biol. 47 (4), 256-263.

Gaido, K.W., Leonard, L S., Lovell, S., Gould, J.C., Babaï, D., Portier, CJ., McDonnell, D. P., 1997. Evaluation of chemicals with endocrine modulating activity in a yeastbased steroid hormone receptor gene transcription assay. Toxicol. Appl. Pharmacol. 143, 205-212.

Gutlebl, A.C., Meerts, I.A.T.M, Bergsma, J.H., Schriks, M., Murk, A.J., 2005. T-screen as a tool to identify thyroid hormone receptor active compounds. Environ. Toxicol. Pharmacol. 19, 231-238.

Gutleb, A.C., Schriks, M., Mossink, L., Berg, J.H., Murk, A.J., 2007. A synchronized amphibian metamorphosis assay as an improved tool to detect thyroid hormone disturbance by endocrine disruptors and apolar sediment extracts. Chemosphere 70, 93-100.

Han, W., Wang, S., Huang, H., Luo, L., Zhang, S., 2013. Simultaneous determination of brominated phenols in soils. J. Environ. Sci. 25 (11), 2306-2312.

Hoefling, M., Lima, N., Haenni, D., Seidel, C.A., Schuler, B., Grubmüller, H., 2011. Structural heterogeneity and quantitative FRET efficiency distributions of polyprolines through a hybrid atomistic simulation and Monte Carlo approach. PLoS One 6, e19791.

Jálová, V., Jarošová, B., Bláha, L., Giesy, J.P., Ocelka, T., Grabic, R., Jurcikova, J., Vrana, B., Hilscherová, K., 2013. Estrogen-, androgen- and aryl hydrocarbon receptor mediated activities in passive and composite samples from municipal waste and surface waters. Environ. Int. 59, 372-383.

Kannan, K., Battula, S., Loganathan, B.G., Hong, C.-S., Lam, W.H., Villeneuve, D.L., Sajwan, K., Giesy, J.P., Aldous, K.M., 2003. Trace organic contaminants including toxaphene and trifluralin in cotton field soils from Georgia and South Carolina, USA. Arch. Environ. Contam. Toxicol. 45, 30-36.

Kirkegaard, M., Sonne, C., Dietz, R., Letcher, R.J., Jensen, A.L., Hansen, S.S., Jenssen, B. M., Grandjean, P., 2011. Alterations in thyroid hormone status in Greenland sledge dogs exposed to whale blubber contaminated with organohalogen compounds. Ecotoxicol. Environ. Saf. 74 (1), 157-163.

Levy-Bimbot, M., Major, G., Courilleau, D., Blondeau, J.P., Levi, Y., 2012. Tetrabromobisphenol-A disrupts thyroid hormone receptor alpha function in vitro: use of fluorescence polarization to assay corepressor and coactivator peptide binding. Chemosphere 87 (7), 782-788.

Li, J., Ma, M., Wang, Z., 2008. A two-hybrid yeast assay to quantify the effects of xenbotics on thyroid hormone-mediated gene expression. Environ. Toxicol. Chem. 27, 159-167.

Li, J., Wang, Z., Ma, M., Peng, X., 2010a. Analysis of environmental endocrine disrupting activities using recombinant yeast assay in wastewater treatment plant effluents. Bull. Environ. Contam. 84, 529-535. 
Li, J., Ren, S., Han, S., Li, N., 2014a. A yeast bioassay for direct measurement of thyroid hormone disrupting effects in water without sample extraction, concentration, or sterilization. Chemosphere 100, 139-145.

Li, J., Li, M., Ren, S., Feng, C., Li, N., 2014b. Thyroid hormone disrupting activities of sediment from the Guanting Reservoir, Beijing, China. J. Hazard. Mater. 274, 191-197.

Li, J., Wang, Y., Kong, D., Wang, J., Teng, Y., Li, N., 2015. Evaluation and characterization of anti-estrogenic and anti-androgenic activities in soil samples along the Second Songhua River, China. Environ. Monit. Assess. 187, 724.

Li, N., Wang, D., Zhou, Y., Ma, M., Li, J., Wang, Z., 2010b. Dibutyl phthalate contributes to the thyroid receptor antagonistic activity in drinking water processes. Environ. Sci. Technol. 44, 6863-6868.

Luo, J., Lei, B., Ma, M., Zha, J., Wang, Z., 2011. Identification of estrogen receptor agonists in sediments from Wenyu River, Beijing, China. Water Res. 45, 3908-3914.

Ma, M., Rao, K.F., Wang, Z.J., 2007. Occurrence of estrogenic effects in sewage and industrial wastewaters in Beijing, China. Environ. Pollut. 147, 331-336.

Mnif, W., Ibn Hadj Hassine, A., Bouaziz, A., Bartegi, A., Thomas, O., Roig, B., 2011. Effect of endocrine disruptor pesticides: a review. Int. J. Environ. Res. Public Health 8, 2265-2303.

Montaño, M., Weiss, J., Hoffmann, L., Gutleb, A.C., Murk, A.J., 2013. Metabolic activation of nonpolar sediment extracts results in enhanced thyroid hormone disrupting potency. Environ. Sci. Technol. 47, 8878-8886.

Murk, A.T.J., Rijntjes, E., Blaauboer, B.J., Clewell, R., Crofton, K.M., Dingemans, M.M., Furlow, J.D., Kavlock, R., Köhrle, J., Opitz, R., Traas, T., Visser, T.J., Xia, M., Gutleb, A.C., 2013. Mechanism-based testing strategy using in vitro approaches for identification of thyroid hormone disrupting chemicals. Toxicol. In Vitro 27, 1320-1346.

National Environmetal Quality standards for Soils of China (GB15618, 1995).

Northcott, G.L., Jones, K.C., 2000. Experimental approaches and analytical techniques for determining organic compound bound residues in soil and sediment. Commentary 108, 19-43.

Robson, T.C., Braungardt, C.B., Keith-Roach, M.J., Rieuwerts, J.S., Worsfold, P.J., 2013. Impact of arsenopyrite contamination on agricultural soils and crops. J. Geochem. Explor. 125, 102-109.

Shi, W., Wei, S., Hu, X.X., Hu, G.J., Chen, C.L., Wang, X.R., Giesy, J.P., Yu, H.X., 2013. Identification of thyroid receptor ant/agonists in water sources using mass balance analysis and Monte Carlo simulation. PLoS One 8, e73883.
Shi, W., Deng, D., Wang, Y., Hu, G., Guo, J., Zhang, X., Wang, X., Giesy, J.P., Yu, H., Wang, Z., 2016. Causes of endocrine disrupting potencies in surface water in East China. Chemosphere 144, 1435-1442.

Skipor, J., Mlynarczuk, J., Szczepkowska, A., Lagaraine, C., Grochowalski, A., Guillaume, D., Dufourny, L., Thiery, J.C., 2012. Photoperiod modulates access of $2,2^{\prime}, 4,4^{\prime}, 5,5^{\prime}$-hexachlorobiphenyl (PCB153) to the brain and its effect on gonadotropin and thyroid hormones in adult ewes. Ecotoxicol. Environ. Saf. 78, 336-343.

Wang, C., Feng, Y., Gao, P., Ren, N., Li, B.L., 2012. Simulation and prediction of phenolic compounds fate in Songhua River, China. Sci. Total Environ. 431, 366-374.

Wang, X., Wang, D., Qin, X., Xu, X., 2008. Residues of organochlorine pesticides in surface soils from college school yards in Beijing, China. J. Environ. Sci. 20 1090-1096.

World Health Organization, 2012. United Nations Environment Programme (WHO UNEP). In: Bergman, A., Heindel, J.J., Jobling, S., Kidd, K.A., Zoeller, R.T., (Eds.), State of the Science of Endocrine Disrupting Chemicals. Available at: 〈http:// www.who.int/ceh/publications/endocrine/en/index.html>.

Wu, Q.Y., Hu, H.Y., Zhao, X., Sun, Y.X., 2009. Effect of chlorination on the estrogenic antiestrogenic activities of biologically treated wastewater. Environ. Sci. Technol. 43, 4940-4945.

Wu, X., Hong, H., Liu, X., Guan, W., Meng, L., Ye, Y., Ma, Y., 2013. Graphene-dispersive solid-phase extraction of phthalate acid esters from environmental water. Sci. Total Environ. 444, 224-230.

Xiao, R., Wang, Z., Wang, C., Yu, G., 2006. Soil screening for identifying ecological risk stressors using a battery of in vitro cell bioassays. Chemosphere 64, 71-78.

Xing, Y., Lu, Y., Dawson, R.W., Shi, Y., Zhang, H., Wang, T., Liu, W., Ren, H., 2005. A spatial temporal assessment of pollution from PCBs in China. Chemosphere 60 731-739.

Xu, P.W., Lou, X.M., Ding, G.Q., Shen, H.T., Wu, L.Z., Chen, Z.J., Han, J.L., Wang, X.F., 2015. Effects of PCBs and PBDEs on thyroid hormone, lymphocyte proliferation, hematology and kidney injury markers in residents of an e-waste dismantling area in Zhejiang, China. Sci. Total Environ. 536, 215-222.

Zhu, Z.C., Chen, S.J., Zheng, J., Tian, M., Feng, A.H., Luo, X.J., Mai, B.X., 2014. Occurrence of brominated flame retardants (BFRs), organochlorine pesticides (OCPs), and polychlorinated biphenyls (PCBs) in agricultural soils in a BFR-manufacturing region of North China. Sci. Total Environ. 481, 47-54. 